\title{
Theoretical and Experimental Evaluation of Tensile Property of Sansevieria Cylindrica Reinforced Wood Waste Biochar Tailored Vinyl Ester Composite
}

\author{
R. Deepak Joel Johnson, V. Arumugaprabu, Tae Jo Ko
}

\begin{abstract}
This research aims to study the tensile property of sansevieria cylindrica reinforced biochar tailored vinyl ester composite (SCBVC) using non-linear regression model, and theoretical model with the empirical tensile properties. Biochar is a carbon rich material produced from the biomass during slow pyrolysis process. In our research wood waste was used to prepare a biochar and influence of biochar particulate loading on the tensile property of the sansevieria cylindrica reinforced vinyl ester composite was studied. Biochar loading up to $6 \mathrm{wt}$ \% $\%$ showed an increase in tensile properties beyond which tensile properties tends to decrease due to agglomeration of biochar particulate. Empirical results were in good correlation with the theoretical models. SEM micrographs showed the failure mechanism of the tensile tested $S C B V C$.
\end{abstract}

Keywords: Biochar, Polymer composite, Sansevieria cylindrica Tensile properties and Theoretical modelling.

\section{INTRODUCTION}

$\mathrm{I}_{\mathrm{n}}$ $n$ recent years it has become necessary to find an effective way dispose or utilize the waste since it can be a major threat in polluting the environment. Especially, huge quantity of wood waste nearly 15 million tonnes were burned for disposal purpose every year in India. Biochar is a carbon rich material produced during slow pyrolysis of biomass. It has become important now a days to model and simulate the polymer-based composite because of its need in development of these material in engineering applications [1]. Two analytical micromechanical model namely series model and Hirsch model were used to predict the tensile properties of the tamarind fruit fibre reinforced polyester composite [2]. Generally, these theories can be classified into two major types depending on the rigidity of the matrix material. Parallel, Series, Hirsch, Halpin Tsai Models comes under rigid polymer matrices $[3,4]$.

Revised Manuscript Received on December 16, 2019.

* V. Arumugaprabu

R. Deepak Joel Johnson, Department of Mechanical Engineering, Saveetha School of Engineering, Saveetha Institute of Medical and Technical Sciences, Saveetha Nagar, Thandalam, Chennai -602 105, Tamil Nadu, India. Email: rdeepakjoeljohnson@gmail.com

V. Arumugaprabu*, School of Automotive and Mechanical Engineering, Kalasalingam Academy of Research and Education, Srivilliputhur - 626 126, Tamil Nadu, India. Email: v.arumugaprabu@klu.ac.in

Tae Jo Ko, School of Mechanical Engineering, Yeungnam University, Gyeongsan-si, South Korea. Email: tjko@yu.ac.kr.
Assumption was made that stress is uniform between the fibre and matrix in case of series model so as to get good correlation between the experimental and theoretical models [5]. Developed models were able to overestimate the properties of the material under study. Thus, it can be utilized by the composite designers to make more appropriate fabrication methods [6]. Among the mechanical properties of the composite materials tensile strength is the most significant for engineering components and structures [7]. Vinyl ester acts as intermediate between the polyester and the epoxy resin which covers the advantages of epoxy resin like good mechanical and thermal properties and low cost and easy to cure like polyester resins [8]. Alkali treatment was done to the sansevieria cylindrica fibres to enhance the mechanical property and thermal degradation of the composite incorporate sansevieria cylindrica as reinforcement [9-11]. Our research focuses on the evaluation of tensile property of the sansevieria cylindrica reinforced biochar tailored vinyl ester composite (SCBVC) experimentally. Three theoretical models were used to forecast the tensile property of the fabricated SCBVC and the correlation between the predicted and the experimental were evaluated. SEM micrographs were taken to study the failure mechanism on the tensile tested SCBVC samples.

\section{MATERIALS AND METHODS}

\section{A. Materials}

Matrix material used for this research is Vinyl ester resin commercial grade VBR 2303 which was purchased from Vasavibala chemicals private ltd. Chennai India. Reinforcing material is sansevieria cylindrica fibre procured from a commercial seller in Coimbatore, Tamil Nadu. Sansevieria cylindrica was cut to $40 \mathrm{~mm}$ length and treated with $5 \%$ $\mathrm{NaOH}$ for a period of 2 hours. Biochar particle is prepared from wood waste by slow pyrolysis process at $600{ }^{\circ} \mathrm{C}$ temperature. Wood waste is collected from the saw mill industries near Rajapalayam, Tamil Nadu, India. The biochar particle after slow pyrolysis process is ball milled to maintain the uniformity in the particle size. Average particle size of the ball milled biochar is $413 \mathrm{~nm}$. 


\section{B. Composite Fabrication}

Biochar filled Vinyl ester composite were fabricated by solution dispersion method by varying the biochar wt. \%. Using glass mould biochar filled vinyl ester composite were fabricated. Sansevieria cylindrica reinforced wood waste biochar tailored vinyl ester composite was fabricated using compression moulding. Steel moulds were used for preparing the composite plates with dimensions $300 \times 130 \times 3 \mathrm{~mm}$.

\section{Tensile Test}

Fabricated composite plates were cut according to ASTM D 3039 standards and tested in universal testing machine to determine the tensile properties of the composite materials.

\section{Theoretical Models}

Theoretical models namely Series model, Hirsch model and Halpin Tsai model were used to forecast the tensile property of the sansevieria cylindrica material. Empirical tensile properties were correlated with the theoretical models to evaluate the agreement between the forecast and empirical tensile properties.

\section{E. Scanning Electron Microscopy}

Zeiss EVO 18 research scanning electron microscope (SEM) was used to determine the failure mechanism on the tensile tested sansevieria cylindrica reinforced biochar tailored vinyl ester composite.

\section{RESULTS AND DISCUSSIONS}

\section{A. Tensile Properties of Biochar tailored vinyl ester composite with and without reinforcement}

The tensile properties of the biochar filled vinyl ester composite (BVC) and sansevieria cylindrica reinforced Biochar tailored vinyl ester composite (SCBVC) were plotted in the graphs shown in Fig. 1 and Fig. 2. It is observed from the graphs that tensile strength tends to increase as the biochar wt. \% increases till 4 wt. \% beyond which tensile strength keeps falling. Tensile modulus of the composites also behaves similarly to the tensile strength for both the composite with and without sansevieria cylindrica. $4 \mathrm{wt}$. \% biochar content to the vinyl ester composite increases the tensile strength and tensile modulus by $33.17 \%$ and $31.37 \%$ for BVC and 33.76 $\%$ and $20.27 \%$ for SCBVC. Maximum tensile strength and tensile modulus of $59.07 \mathrm{MPa}$ and $0.89 \mathrm{GPa}$ was observed for the 4 wt. \% SCBVC material.

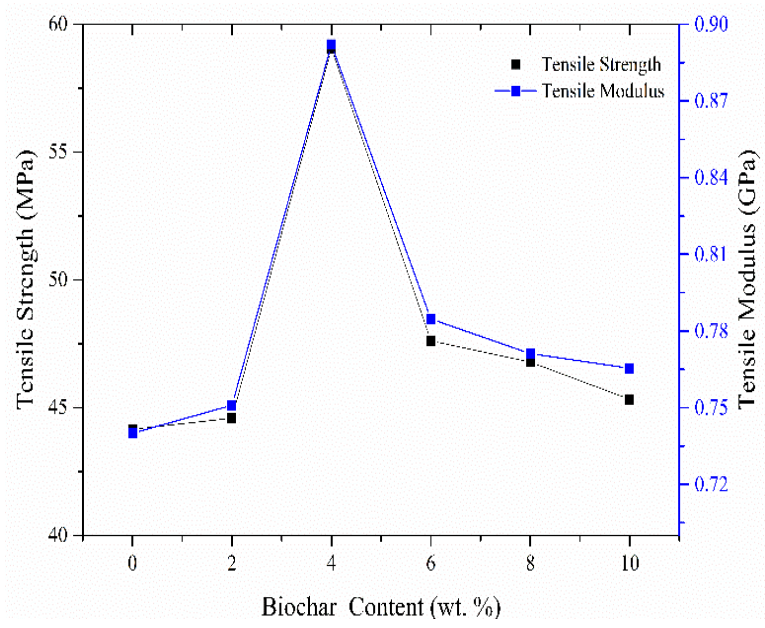

Fig. 1: Tensile properties of BVC

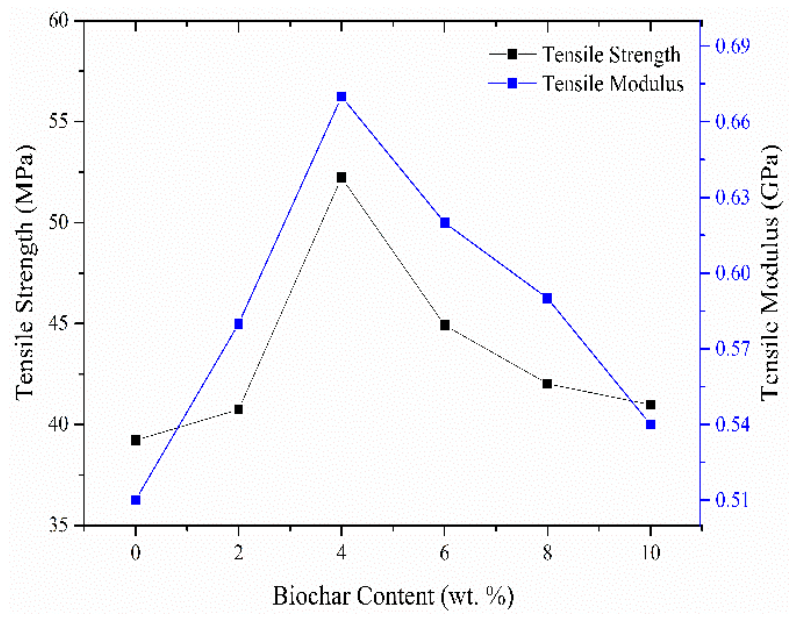

Fig. 2: Tensile Properties of SCBVC

Addition of biochar particulate to the vinyl ester matrix material to certain weight percentage improves the tensile properties of the composite. This proves the significance of wood waster biochar particulate as the filler material to improve the strength and stiffness of the composite material. Presence of high content stable carbon in the prepared wood waste biochar will be the reason for the improves strength and stiffness of composite material incorporating biochar as filer material.

\section{B. Theoretical Models to predict the tensile strength and tensile modulus of the SCBVC}

To predict the tensile properties of the SCBVC three most effective models namely Series, Hirsch and Halpin Tsai were used in our research. Series model to determine the tensile properties of the SCBVC is as follows,

$$
\begin{gathered}
T_{S C B V C}=\frac{T_{f} T_{m}}{T_{m} V_{f}+T_{f} V_{m}} \\
M_{S C B V C}=\frac{M_{f} M_{m}}{M_{m} V_{f}+M_{f} V_{m}}
\end{gathered}
$$

Equation (3) \& (4) shows the Hirsch model to evaluate the tensile properties of the SCBVC. In equation (3) \& (4) $X$ is the efficient stress transfer factor which theatres a minor role in predicting the tensile strength and taken as 0.01. Best fit between the empirical and theoretical values can be achieved only when the value of $x$ is 0.01 .

$$
T_{S C B V C}=x\left(T_{m} V_{m}+T_{f} V_{f}\right)+(1-x) \frac{T_{f} T_{m}}{T_{m} V_{f}+T_{f} V_{m}}
$$




$$
M_{S C B V C}=x\left(M_{m} V_{m}+M_{f} V_{f}\right)+(1-x) \frac{M_{f} M_{m}}{M_{m} V_{f}+M_{f} V_{m}}
$$

$\mathrm{T} \& \mathrm{M}$ in equation (1), (2), (3) \& (4) denotes the tensile strength and the tensile modulus of $\mathrm{m}$ - matrix material; $\mathrm{f}$ - fibre material and SCBVC- composite material.

Halpin Tsai Model for calculating the tensile strength and tensile modulus of the composite is conferred as,

$$
\begin{gathered}
T_{S C B V C}=T_{m}\left(\frac{1+A \eta V_{f}}{1-\eta V_{f}}\right) \\
\eta=\frac{T_{f} / T_{m}-1}{T_{f} / T_{m}+A} \\
M_{S C B V C}=M_{m}\left(\frac{1+A \eta V_{f}}{1-\eta V_{f}}\right) \\
\eta=\frac{M_{f} / M_{m}-1}{M_{f} / M_{m}+A}
\end{gathered}
$$

$\mathrm{T} \& \mathrm{M}$ in equation (5), (6), (7) \& (8) denotes the tensile strength and the tensile modulus of $\mathrm{m}$ - matrix material; f- fibre material and SCBVC- composite material. $\eta$ is the stress partitioning factor which can be calculated from equation (8), $A$ is the reinforcing efficiency which is maintained as 0.1 . Fig. 3(A) \& (B) shows the correlation between the predicted tensile strength and modulus from three theoretical models and the empirical values of the sansevieria cylindrica reinforced biochar tailored vinyl ester composite. The tensile strength predicted from the Series Model showed very good correlation with empirical values compared to the other models and the fit goes on like Series Model > Halpin Tsai Model > Hirsch Model.

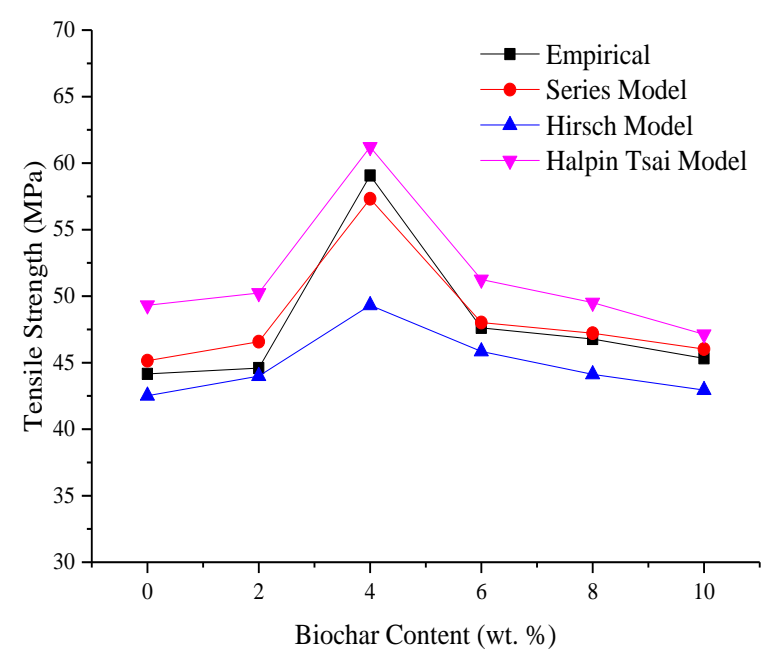

Fig. 3(A): Correlating Empirical Tensile Strength with the Theoretical Models

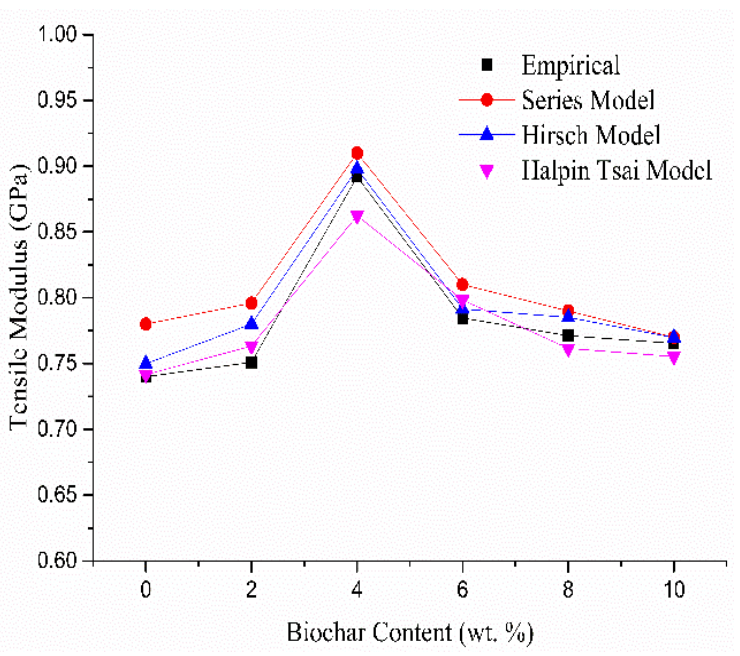

Fig. 3(B): Correlating Empirical Tensile Modulus with the Theoretical Models

Whereas in case of the tensile modulus the Hirsch Model gave good correlation with the empirical model and the fit goes like Hirsch Model > Series Model > Halpin Tsai Model. It was also noted that similar trend was seen on the rise and fall of the tensile strength as well as tensile modulus for the predicted and the empirical values.

\section{Scanning Electron Microscopy Analysis}

Tensile tested samples were analysed for its failure under scanning electron microscopy. Fig. 4 reveals the various failure mechanism on the tensile tested specimens of the SCBVC material. It was observed that 4 wt. \% wood waste Biochar filled composite material has better bonding strength than the unfilled composite resulting in improved tensile properties of the composites.

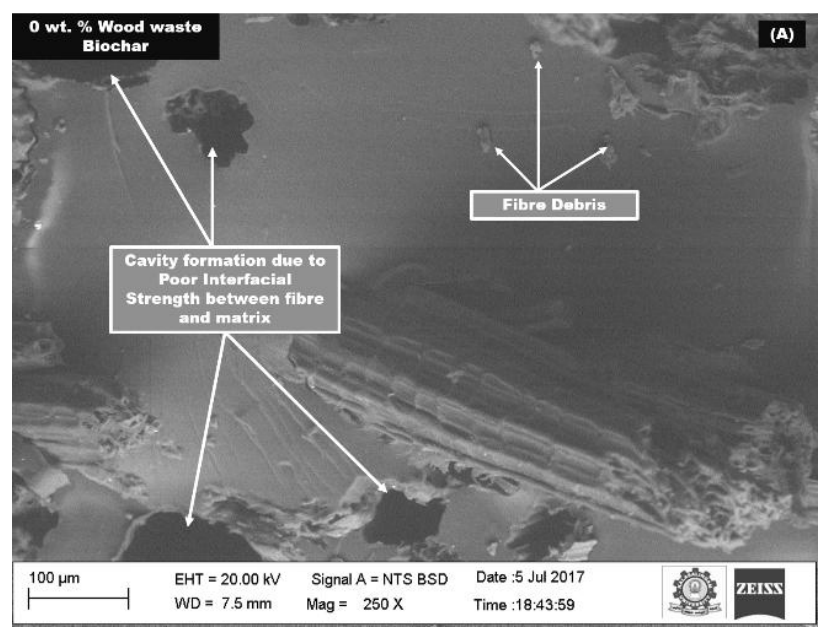

Fig. 4(A): SEM Micrograph of Tensile tested SCBVC material for 0 wt. \% wood waste Biochar

Published By:

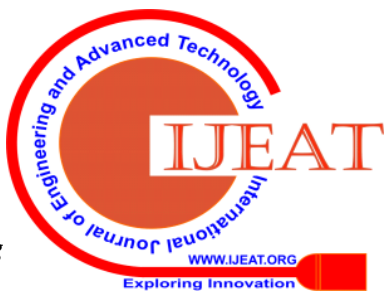




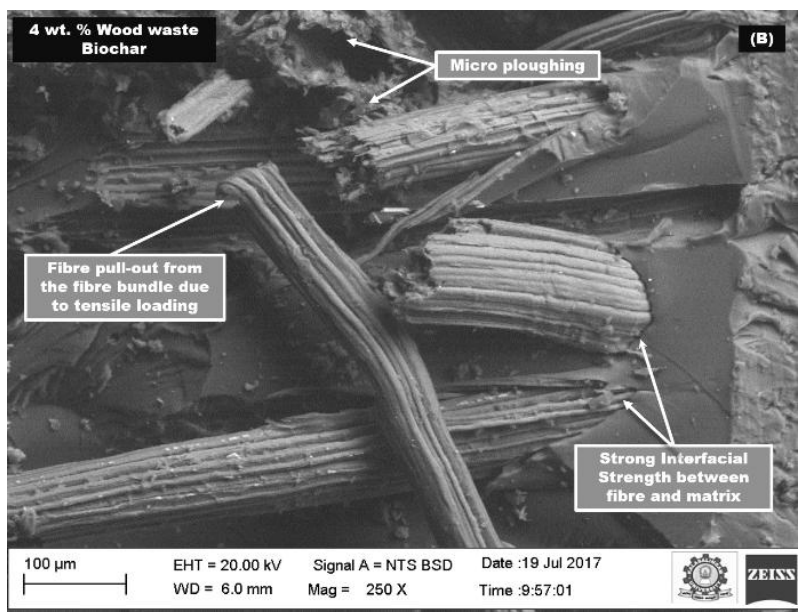

Fig. 4(B): SEM Micrograph of Tensile tested SCBVC material for $4 \mathrm{wt}$. \% of wood waste Biochar

\section{CONCLUSIONS}

The following conclusions were made from the evaluation on the tensile property of the SCBVC.

- Tensile properties increase as the biochar content increases till 4 wt. $\%$ and decreases as the biochar content goes beyond 4 wt. \% due to agglomeration. Also, there was an increase of $33.76 \%$ and $20.27 \%$ in tensile strength and tensile modulus compared to the unfilled composite.

- It was inferred from the predicted values of the theoretical models that tensile strength and tensile modulus determined empirically were in good agreement with the theoretical models.

- SEM micrograph reveals that 4 wt. \% wood waste biochar filled composite has good interfacial adhesion between fibre and matrix material compared with the unfilled composite.

\section{REFERENCES}

1. P. K. Valavala and G. M. Odegard, "Modeling techniques for determination of mechanical properties of polymer nanocomposites," Rev. Adv. Mater. Sci, vol. 9(34), 2005, pp. e44.

2. J. S. Binoj, R. E. Raj and B. S. S. Daniel, "Comprehensive characterization of industrially discarded fruit fiber, Tamarindus indica L. as a potential eco-friendly bio-reinforcement for polymer composite," Journal of cleaner production, vol. 142, 2017, pp.1321-1331.

3. G. Kalaprasad, K. Joseph, S. Thomas C. Pavithran, "Theoretical modelling of tensile properties of short sisal fibre-reinforced low-density polyethylene composites," Journal of Materials Science, vol. 32(16), 1997, pp.4261-4267.

4. V. Arumugaprabu and Y. S. Munde, "Constitutive models to predict the mechanical performance of sansevieria cylindrica reinforced vinyl ester composite," Materials Research Express, vol. (9), 2019, pp. 095310.

5. P. V. Joseph, G. Mathew, K. Joseph, S. Thomas and P. Pradeep, "Mechanical properties of short sisal fiber- reinforced polypropylene composites: Comparison of experimental data with theoretical predictions," Journal of Applied Polymer Science, vol. 88(3), 2003, pp.602-611.

6. M. Kim, Y. B. Park, O. I. Okoli and C. Zhang, "Processing, characterization, and modeling of carbon nanotube-reinforced multiscale composites," Composites Science and Technology, vol. 69, 2009, pp.335-342.
7. S. S. Shinde, A. V. Salve and S. Kulkarni, "Theoretical modeling of mechanical properties of woven jutefiber reinforced polyurethanecomposites," Materials Today: Proceedings, vol. 4(2), 2017, pp.1683-1690.

8. R. D. J. Johnson, V. Arumugaprabu and T. J. Ko, "Mechanical Property, Wear Characteristics, Machining and Moisture Absorption Studies on Vinyl Ester Composites-a Review," Silicon, 2018, pp.1-16.

9. M. A. Kumar, K. H. Reddy, G. R. Reddy and K. V.Mahesh, Charantarization of lisht waicht annver somnocitas from shor Sansevieria Cylindrica fibers," Fibers and Polymers, vol. 13(6), 2012, pp.769-774.

10. V. S. Sreenivasan, S. Somasundaram, D. Ravindran, V. Manikandan, and R. Narayanasamy, "Microstructural, physico-chemical and

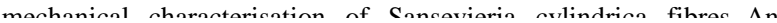
exploratory investigation," Materials \& Design, 32(1), 2011, pp.453-461.

11. T. P. Sathishkumar, P. Navaneethakrishnan and S. Shankar, "Tensile and flexural properties of snake grass natural fiber reinforced isophthallic polyester composites," Composites Science and Technology, vol. 72(10), 2012, pp.1183-1190.

\section{AUTHORS PROFILE}

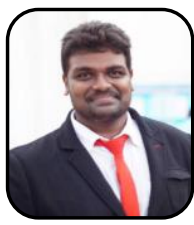

R. Deepak Joel Johnson has perused Bachelor's degree in Mechanical Engineering and Master of Technology in Mechanical Engineering with Manufacturing Engineering as Specialization from Karunya University, India. With two years of experience as Assistant Professor in M. Kumarasamy College of Engineering, Karur and he has completed his $\mathrm{PhD}$ in the field of Polymer Composite at Kalasalingam University, India in the year 2019. Currently he is working as Assistant Professor, Department of Mechanical Engineering, Saveetha School of Engineering, SIMATS, Chennai, India. He has more than 15 International Publication in reputed Journals. His areas of interests are Polymer composites, Bio composites, Optimization techniques, Cutting Fluid Application, Composite machining.

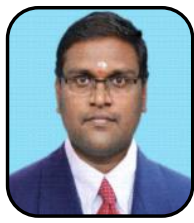

V. Arumugaprabu works as associate professor in the Department of Mechanical Engineering, School of Automotive and Mechanical Engineering, Kalasalingam Academy of Research and education, Krishnankoil, Tamil Nadu, India. Also worked as Post Doc Research Associate in Precision Machining Lab, School of Mechanical Engineering, Yeungnam University, South Korea in the year 2017. He has very vast research experience in the field of composite materials with nearly 25 publications in various reputed SCI Journals and has nearly 40 publications in various International and National conferences.

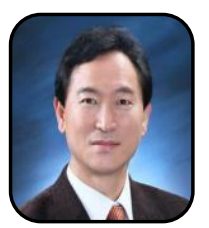

Tae Jo Ko is a Professor of Mechanical Engineering at Yeungnam University, Korea. He received his bachelor and master's degrees from the Pusan National University, Korea. He got Ph.D in mechanical engineering from POSTECH, S. Korea. He has worked for Doosan Infracore Co. Ltd. (formerly Daewoo) from 1985 to 1995. Also, he was responsible for the Gyoungbuk Hybrid Technology Institute that is regional research innovation center and initiated the idea for hybrid manufacturing. His research interest include machine tools, metal cuttings as well as non-traditional machining Recently, he launched the research of surface texturing using metal cutting and grinding. 